\title{
Salmonella enterica serotype Paratyphi A carrying CTX-M-15 type extended-spectrum beta-lactamase isolated from a Japanese traveller returning from India, Japan, July 2013
}

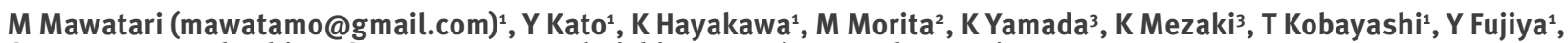

S Kutsuna ${ }^{1}$, N Takeshita ${ }^{1}$, S Kanagawa ${ }^{1}$, M Ohnishi², H Izumiya², N Ohmagari'

1. Disease Control and Prevention Center, National Center for Global Health and Medicine, Tokyo, Japan

2. Bacteriology I, National Institute of Infectious Diseases, Tokyo, Japan

3. Clinical Laboratory, National Center for Global Health and Medicine, Tokyo, Japan

Citation style for this article:

Mawatari M, Kato Y, Hayakawa K, Morita M, Yamada K, Mezaki K, Kobayashi T, Fujiya Y, Kutsuna S, Takeshita N, Kanagawa S, Ohnishi M, Izumiya H, Ohmagari N. Salmonella enterica serotype Paratyphi A carrying CTX-M-15 type extended-spectrum beta-lactamase isolated from a Japanese traveller returning from India, Japan, July 2013. Euro Surveill. 2013;18(46):pii=20632. Available online: http://www.eurosurveillance.org/ViewArticle.aspx?Articleld=20632

Emerging drug resistance in Salmonella Typhi and $S$. Paratyphi is a substantial public health concern. We report what appears to be the first case and isolation of multidrug resistant $S$. Paratyphi A carrying CTXM-15-type extended-spectrum beta-lactamase from a Japanese traveller returning from India.

Here, we report the isolation of multidrug resistant $S$. Paratyphi A producing CTX-M-15-type extended-spectrum beta-lactamase (ESBL) from a traveller returning from India. To our knowledge, this is the first report of S. Paratyphi A with CTX-M-15-type ESBL isolated from a human. Enteric fever, including typhoid fever caused by $S$. enterica serotype Typhi (S. Typhi) and paratyphoid fever caused by $S$. enterica serotype Paratyphi A (S. Paratyphi A), is one of the most important febrile illnesses in tropical and subtropical countries, with high rates of morbidity and mortality [1]. In industrialised countries, enteric fever is a common cause of fever in returned travellers [2]. The emergence of drugresistance in S. Typhi and S. Paratyphi A is an emerging public health problem. Owing to the recent increase of fluoroquinolone resistance, third-generation cephalosporins, such as ceftriaxone or cefotaxime, have become the primary drugs for treatment of enteric fever [3].

\section{Case report}

In July 2013, a Japanese woman in her mid-20s was admitted to a hospital in Manali, India for fever over $38.5^{\circ} \mathrm{C}$, diarrhoea, and anorexia, where she was diagnosed with typhoid fever based on clinical symptoms and a non-specified rapid serological test. She had been in India for five weeks prior to the admission. Before her visit to India, she had been on a seven-week trip to China, Myanmar, Thailand, and Nepal. She was treated with parenteral cephalosporin for three days.
No further details on the treatment regimen in India were available. The patient returned to Japan on day 4 of illness owing to sustained fever, diarrhoea, and anorexia. During her travel from India to Japan (days 5-7), the patient took oral combined ofloxacin-cefixime. On day 7 , she was admitted to our hospital with diarrhoea and anorexia but without fever. On examination, deep palpation of the lower abdominal area caused mild discomfort, otherwise, physical examination was normal. She did not have any underlying illness, and was not on any regular medication. Eight months prior to the admission at the hospital in India she had been vaccinated against Salmonella Typhi (Vi polysaccharide).

\section{Laboratory analyses}

On admission, stool and blood samples were taken for culture. Antimicrobial susceptibility test was performed by broth microdilution in accordance with the Clinical and Laboratory Standards Institutes [4].

The patient's stool was screened on admission for meticillin-resistant Staphylococcus aureus, vancomycinresistant Enterococci, and Gram-negative rods resistant to one or multiple agents in the extended-spectrum cephalosporin class and/or that demonstrated elevated minimum inhibitory concentrations (MICs) $(>1 \mathrm{mg} / \mathrm{L})$ to imipenem and/or meropenem. Screening culture of stool was positive only for drug-sensitive Escherichia coli and Enterobacteriaceae spp.

Results from blood cultures were positive for S. Paratyphi A two days after admission and S. Paratyphi A was found to be resistant to cefotaxime (MIC $=64$ $\mathrm{mg} / \mathrm{L}$ ) and ceftazidime (MIC >16 mg/L). Addition of clavulanic acid to each cephalosporin lowered the MIC to $0.25 \mathrm{mg} / \mathrm{L}$ and $1 \mathrm{mg} / \mathrm{L}$, respectively. This isolate was also resistant to nalidixic acid, and categorised as 
TABLE

Minimum inhibitory concentrations of various antibiotics on Salmonella enterica serotype Paratyphi A isolated from a Japanese traveller returning from India, Japan, July 2013

\begin{tabular}{|l|c|}
\hline Antibiotics & $\begin{array}{c}\text { MIC (mg/L), } \\
\text { interpretation result }\end{array}$ \\
\hline Ampicillin & $>16, \mathrm{R}$ \\
\hline Amoxicillin/clavulanic acid & $=16, \mathrm{I}$ \\
\hline Cefotaxime & $=0.25, \mathrm{~S}$ \\
\hline Cefotaxime/clavulanic acid & $>16, \mathrm{R}$ \\
\hline Ceftazidime & $=1, \mathrm{~S}$ \\
\hline Ceftazidime/clavulanic acid & $>16, \mathrm{R}$ \\
\hline Ceftriaxone & $>16, \mathrm{R}$ \\
\hline Nalidixic acid & $=0.5, \mathrm{I}$ \\
\hline Ciprofloxacin & $=1, \mathrm{I}$ \\
\hline Levofloxacin & $=16^{\mathrm{a}}$ \\
\hline Azithromycin & $>16, \mathrm{R}$ \\
\hline Aztreonam & $>2, \mathrm{R}$ \\
\hline Trimethoprim/sulfamethoxazole & $=4, \mathrm{~S}$ \\
\hline Chloramphenicol & $=2, \mathrm{~S}$ \\
\hline Tetracycline & \\
\hline
\end{tabular}

MIC: Minimum inhibitory concentration; R: resistant; S: susceptible; I: intermediate.

a The MIC breakpoint for azithromycin is not provided by the Clinical and Laboratory Standards Institutes. We thus refer to the breakpoints table by the European Committee on Antimicrobial Susceptibility Testing, which mentions that azithromycin has been used in the treatment of infections with Salmonella Typhi (MIC $<16 \mathrm{mg} / \mathrm{L}$ for wild type isolates) [15].

intermediate to ciprofloxacin (Table). Due to the atypical susceptibility pattern and the requirement for the verification susceptibility test process, it took longer than one week for the final susceptibility result to be available.

The presence of the gene conferring the ESBL phenotype was verified by polymerase chain reaction (PCR) as described elsewhere [5]. Sequencing of the PCR products revealed that $S$. Paratyphi $A$ was positive for bla $_{\mathrm{CTX}-\mathrm{M}-15}$. The presence of the plasmid-mediated quinolone resistance genes including $q n r A$, $q n r B$, qnrC, qnrS, and $a a c\left(6^{\prime}\right)-1 b$ was investigated using PCR described elsewhere [6-9]. However plasmid-mediated quinolone resistance genes were not detected in this isolate.

\section{Patient treatment and outcome}

Upon admission, we treated the patient with ceftriaxone ( 2 g per day for 8 days), and the patient's symptoms resolved after eight days of admission. After the final susceptibility results were available, the initial antibiotic treatment was changed on day 9 from ceftriaxone to azithromycin (orally, $500 \mathrm{mg}$ per day), which was administered for seven days. A stool culture obtained on admission was negative for S. Paratyphi A. Stool cultures repeated before changing antibiotic treatment as well as eight, nine, and 10 days after completing azithromycin treatment also remained negative for S. Paratyphi A. The patient was discharged on 10 days after admission.

\section{Discussion and conclusion}

Although ESBL-producing organisms are emerging among Enterobacteriaceae, ESBL-producing S. Typhi or $S$. Paratyphi A have been reported rarely in Nepal and the Middle East $[10,11]$; CTX-M-15 type ESBL-producing $S$. Typhi were previously reported in patients in Middle Eastern countries $[11,12]$.

bla $a_{\mathrm{CTX}-\mathrm{M}-15}$ genes have been identified worldwide in Enterobacteriaceae; further, isolation of these genes from Escherichia coli has been reported to be increasing [13]. The acquisition of bla $a_{\mathrm{CTX}-\mathrm{M}-15}$ as a transferable plasmid from another enteric bacterium has previously been reported in S. Typhi [5].

Of particular concern are reports of increasing isolation rates of $S$. Paratyphi A from India and other parts of Asia [14], which might be attributed to use of protective vaccines (Vi polysaccharide and live oral Ty21a) effective against S. Typhi, but not S. Paratyphi A [14].

The number of reports on ESBL in S. Typhi and S. Paratyphi A is still limited, and thus, extendedspectrum cephalosporins would still be a reasonable empiric treatment for a suspected case of enteric fever in the current situation. The patient improved on day 8 before antibiotics were changed. The oral treatment by a fluoroquinolone (ofloxacin) prior to the admission might have contributed to her clinical improvement. Other possible explanations include clinical recovery by natural history of $S$. Paratyphi A, or infection of two different antimicrobial patterns of $S$. Paratyphi A, i.e. ESBL-S. Paratyphi A and non-ESBL-S. Paratyphi A, with non-ESBL mainly contributing to clinical symptoms.

Potential increase in the plasmid-mediated spread of ESBL in S. Paratyphi A in the future would pose a threat to public health. Judicious use of antibiotics to avoid unnecessary selective pressure on intestinal bacterial flora, and careful microbiological analysis of patients with typhoid fever, especially those returning from the Middle East or south Asia are approaches critical for prevention of the potential spread of multidrug resistant S. Paratyphi A.

\section{Acknowledgements}

This work was partly supported by funding from the Research on Emerging and Reemerging Infectious Diseases by the Ministry of Health, Labour, and Welfare, Japan (H24-shinkou-ippan-013). 


\section{Conflict of interest}

None declared.

\section{Authors' contributions}

M. Mawatari collected the data and drafted the manuscript; YK and KH participated in the coordination and concept of the manuscript and edited the manuscript and helped with the draft of the manuscript; $\mathrm{M}$. Morita, $\mathrm{MO}$ and $\mathrm{HI}$ performed and analysed the molecular tests; $K Y$ and $K M$ performed and analysed the microbiological tests; TK, YF, S. Kutsuna and NT collected the data and participated in the concept of the manuscript; S. Kanagawa and NO revised the article for intellectual content. All authors read and critically revised the first as well as the subsequent and final drafts of this manuscript.

\section{References}

1. Crump JA, Luby SP, Mintz ED. The global burden of typhoid fever. Bull World Health Org. 2004;82(5):346-53. PMid:15298225 PMCid:PMC2622843

2. Leder K, Torresi J, Libman MD, Cramer JP, Castelli F, Schlagenhauf $\mathrm{P}$, et al. GeoSentinel surveillance of illness in returned travelers, 2007-2011. Ann Intern Med. 2013;158(6):456-68. http://dx.doi.org/10.7326/0003-4819-158-6-201303190-00005 PMid:23552375

3. Humphries RM, Fang FC, Aarestrup FM, Hindler JA. In vitro susceptibility testing of fluoroquinolone activity against Salmonella: recent changes to CLSI standards. Clin Infect Dis. 2012;55(8):1107-13. http://dx.doi.org/10.1093/cid/cis6oo PMid:22752519

4. Clinical and Laboratory Standards Institute (CLSI). Performance standards for antimicrobial susceptibility testing; twentysecond informational supplement. M100-S22. Wayne, PA: CLSI; 2012.

5. Morita M, Takai N, Terajima J, Watanabe H, Kurokawa M, Sagara H, et al. Plasmid-mediated resistance to cephalosporins in Salmonella enterica serovar Typhi. Antimicrob Agents Chemother. 2010;54(9):3991-2. http://dx.doi.org/10.1128/AAC.00225-10 PMid:20585124 PMCid:PMC2935013

6. Kim HB, Park CH, Kim CJ, Kim EC, Jacoby GA, Hooper DC. Prevalence of plasmid-mediated quinolone resistance determinants over a 9-year period. Antimicrob Agents Chemother. 2009;53(2):639-45.

http://dx.doi.org/10.1128/AAC.01051-08 PMid:19064896 PMCid:PMC2630623

7. Cattoir V, Poirel L, Rotimi V, Soussy CJ, Nordmann P. Multiplex PCR for detection of plasmid-mediated quinolone resistance qnr genes in ESBL-producing enterobacterial isolates. J Antimicrob Chemother. 2007;60(2):394-7. http://dx.doi.org/10.1093/jac/dkm204 PMid:17561500

8. Park CH, Robicsek A, Jacoby GA, Sahm D, Hooper DC Prevalence in the United States of aac(6')-Ib-cr encoding a ciprofloxacin-modifying enzyme. Antimicrob Agents Chemother. 2006;50(11):3953-5. http://dx.doi.org/10.1128/AAC.00915-06 PMid:16954321 PMCid:PMC1635235

9. Robicsek A, Strahilevitz J, Sahm DF, Jacoby GA, Hooper DC. qnr prevalence in ceftazidime-resistant Enterobacteriaceae isolates from the United States. Antimicrob Agents Chemother. 2006;50(8):2872-4.

http://dx.doi.org/10.1128/AAC.01647-05 PMid:16870791 PMCid:PMC1538681

10. Pokharel BM, Koirala J, Dahal RK, Mishra SK, Khadga PK, Tuladhar NR. Multidrug-resistant and extended-spectrum beta-lactamase (ESBL)-producing Salmonella enterica (serotypes Typhi and Paratyphi A) from blood isolates in Nepal: surveillance of resistance and a search for newer alternatives. Int J Infect Dis. 2006;10(6):434-8. http://dx.doi.org/10.1016/j.ijid.2006.07.001 PMid:16978898

11. Rotimi VO, Jamal W, Pal T, Sovenned A, Albert MJ. Emergence of CTX-M-15 type extended-spectrum beta-lactamase-producing Salmonella spp. in Kuwait and the United Arab Emirates. J Med Microbiol. 2008;57(Pt 7):881-6. http://dx.doi.org/10.1099/jmm.0.47509-0 PMid:18566147

12. Pfeifer Y, Matten J, Rabsch W. Salmonella enterica serovar Typhi with CTX-M beta-lactamase, Germany. Emerg Infect Dis. 2009;15(9):1533-5

http://dx.doi.org/10.3201/eid1509.090567

PMid:19788837 PMCid:PMC2819882

13. Pitout JD, Laupland KB. Extended-spectrum beta-lactamase producing Enterobacteriaceae: an emerging public-health concern. Lancet Infect Dis. 2008;8(3):159-66. http://dx.doi.org/10.1016/S1473-3099(08)70041-0

14. Ochiai RL, Wang X, von Seidlein L, Yang J, Bhutta ZA, Bhattacharya SK, et al. Salmonella paratyphi A rates, Asia. Emerg Infect Dis. 2005;11(11):1764-6.

http://dx.doi.org/10.3201/eid1111.050168 PMid:16318734 PMCid:PMC3367370

15. The European Committee on Antimicrobial Susceptibility Testing (EUCAST). Breakpoint tables for interpretation of MICs and zone diameters Version 3.1, valid from 2013-02-11. Växjö: EUCAST; 2013. Available from: http://www.eucast.org/ fileadmin/src/media/PDFs/EUCAST_files/Breakpoint_tables/ Breakpoint table_v 3.1.pdf 